\title{
Analysis of xanthyletin and secondary metabolites from Pseudomonas stutzeri ST1302 and Klebsiella pneumoniae ST2501 against Pythium insidiosum
}

Kittiya Wittayapipath ${ }^{1}$, Saline Laolit ${ }^{1}$, Chavi Yenjai ${ }^{2}$, Sirinart Chio-Srichan ${ }^{3}$, Maitree Pakarasang ${ }^{1}$, Ratree Tavichakorntrakool ${ }^{1}$ and Chularut Prariyachatigul ${ }^{1 *}$

\begin{abstract}
Background: Pythium insidiosum is a member of the oomycetes class of aquatic fungus-like microorganisms. It can infect humans and animals through skin wounds and the eyes, causing pythiosis, an infectious disease with high morbidity and mortality rates. Antifungal agents are ineffective as pythiosis treatments because ergosterol, the target site of most antifungal agents, is not found in the P. insidiosum cytoplasmic membrane. The best choice for treatment is surgical removal of the infected organ. While natural plant products or secretory substances from bacterial flora have exhibited in vitro anti-P. insidiosum activity, their mechanism of action remains unknown. Therefore, this study hypothesized that the mechanism of action could be related to changes in P. insidiosum biochemical composition (such as lipid, carbohydrate, protein or nucleic acid) following exposure to the inhibitory substances. The biochemical composition of $P$. insidiosum was investigated by Synchrotron radiation-based Fouriertransform infrared (FTIR) microspectroscopy.

Results: Fraction No.6 from the crude extract of P. stutzeri ST1302, fraction No.1 from the crude extract of $K$. pneumoniae ST2501 and xanthyletin were used as anti-P. insidiosum substances, with MFCs at 3.125, 1.57-1.91, 0. $003 \mathrm{mg} / \mathrm{ml}$, respectively. The synchrotron FTIR results show that the deconvoluted peak distributions in the amide I, amide II, and mixed regions were significantly different between the treatment and control groups.

Conclusions: Xanthyletin and the secondary metabolites from P. stutzeri ST1302 and K. pneumoniae ST2501 exerted anti-P. insidiosum activity that clearly changed the proteins in P. insidiosum. Further study, including proteomics analysis and in vivo susceptibility testing, should be undertaken to develop a better understanding of the mechanism of anti-P. insidiosum activity.
\end{abstract}

Keywords: P. insidiosum, P. stutzeri ST1302, K. pneumoniae ST2501, Xanthyletin, Synchrotron radiation-based Fouriertransform infrared (FTIR) microspectroscopy

\footnotetext{
* Correspondence: chupra@kku.ac.th

${ }^{1}$ Department of Clinical Microbiology, Faculty of Associated Medical Sciences,

Centre for Research and Development of Medical Diagnosis Laboratories,

Khon Kaen University, Khon Kaen 40002, Thailand

Full list of author information is available at the end of the article
}

(c) The Author(s). 2019 Open Access This article is distributed under the terms of the Creative Commons Attribution 4.0 International License (http://creativecommons.org/licenses/by/4.0/), which permits unrestricted use, distribution, and reproduction in any medium, provided you give appropriate credit to the original author(s) and the source, provide a link to the Creative Commons license, and indicate if changes were made. The Creative Commons Public Domain Dedication waiver (http://creativecommons.org/publicdomain/zero/1.0/) applies to the data made available in this article, unless otherwise stated. 


\section{Background}

Pythium insidiosum is a member of the oomycete class of aquatic fungus-like microorganisms. It can infect both humans and animals through the eyes or skin wounds to cause pythiosis, a disease with severe morbidity and high mortality rates $[1,2]$. Hosts become infected after biflagellate zoospores that found in wetland areas attach to a skin wound $[1,3,4]$. The clinical manifestations are comprised of cutaneous and subcutaneous forms, vascular form, ocular form, and disseminated pythiosis. The treatment options that have been employed for pythiosis include antifungal agents, radical surgery, and immunotherapy. However, these treatments have not been successful in all cases $[1,5]$. Most antifungal agents are ineffective because $P$. insidiosum lacks ergosterol in the cytoplasmic membrane, the target site of antifungal agents, which act by interfering with ergosterol synthesis and its function in the membrane [1]. The most effective treatment protocol for both humans and animals with pythiosis is radical surgery, but patients can suffer from serious disabilities $[2,6]$. Interestingly, the biological control works by reducing the numbers of pests or eliminating pest organisms by interfering with their ecological status through the introduction a natural competition or pathogen into the environment. Natural plant products and secretory substances from bacterial flora have been reported to have in vitro anti- $P$. insidiosum activity. A new furanocoumarin isolated from the fruit of Scaevola taccada and secondary metabolites from Pseudomonas stutzeri and Klebsiella pneumoniae that were collected from swampy areas have also been found to exhibit in vitro inhibitory effects on the human pathogenic oomycete $P$. insidiosum $[7,8]$. Nonetheless, the precise mechanism of this inhibitory effect remains unknown.

Synchrotron Fourier-transform infrared (FTIR) microspectroscopy utilizes infrared (IR) radiation from a synchrotron light source that is transmitted through an interferometer to irradiate a sample and cause biomolecular vibrations. Biomolecules have unique vibrational characteristics which correspond to specific infrared light frequencies that are related to their functional groups [9-11]. FTIR spectra can provide an informative semi-quantitative overview of the lipid, protein, carbohydrate or nucleic acid components of a biological sample. This technique is a proven and accepted tool for the study of biological samples. The present study therefore used synchrotron FTIR microspectroscopy to study the biochemical composition changes in $P$. insidiosum after the organism was exposed to inhibitory substances, based on the presumption that these changes would reflect the mechanism of its inhibitory activity.

\section{Results}

Crude extraction from $P$. stutzeri ST1302 and $K$. pneumoniae ST2501

The crude extracts from P. stutzeri ST1302 and K. pneumoniae ST2501 were divided into 14 and 5 fractions, respectively. Fraction No.6 (yellow solid) of the crude extract from P. stutzeri ST1302 was eluted with $20 \%$ methanol in dichloromethane, while fraction No.1 (brown semisolid) of the crude extract from K. pneumoniae ST2501 was eluted with 100\% dichloromethane gave the strongest anti- $P$. insidiosum activity. Both the crude extract and fraction No.1 from the crude extract of $K$. pneumoniae ST2501 gave stronger anti- $P$. insidiosum activity and stability results than P. stutzeri ST1302.

\section{Anti-P. insidiosum activity and minimum fungicidal concentration}

Xanthyletin and the crude extracts from $P$. stutzeri ST1302 and K. pneumoniae ST2501 showed anti-P. insidiosum activity against all eleven of the clinical strains of $P$. insidiosum by disc diffusion method. The MFCs were $3.125,1.57-1.91$ and $0.003 \mathrm{mg} / \mathrm{ml}$ for fraction No.6 from the crude extract of $P$. stutzeri ST1302, fraction No.1 from the crude extract of $K$. pneumoniae ST2501, and xanthyletin, respectively (Table 1 ).

\section{Synchrotron radiation-based FTIR microspectroscopy}

The spectral profile provided information about the biochemical composition and corresponded with important macromolecules such as the proteins, lipids, and carbohydrates of filamentous P. insidiosum (Fig. 1). Firstly, the region between 3000 and $2800 \mathrm{~cm}^{-1}$ demonstrates the $\mathrm{C}-\mathrm{H}$ stretching vibrations of $\mathrm{CH}_{3}$ and $\mathrm{CH}_{2}$ functional groups in fatty acid chains of the diverse membrane, such as phospholipids. The next region, from 1800 to $1500 \mathrm{~cm}^{-1}$, shows the stretching vibrations of $\mathrm{C}=\mathrm{O}, \mathrm{CN}$ and bending mode of $\mathrm{NH}$ in amide $\mathrm{I}$ and the $\mathrm{C}-\mathrm{N}$ stretching vibrations and bending mode in amide II. Subsequently, the region between 1500 and $1200 \mathrm{~cm}^{-1}$ which represents a mixed region that exhibited $\mathrm{C}=\mathrm{O}$ symmetric stretching vibrations of $-\mathrm{COO}^{-}$functional groups of amino acid side chains or free fatty acids, $\mathrm{CH}_{2}$ bending mode of lipids and proteins, and $\mathrm{P}=\mathrm{O}$ asymmetric stretching vibrations in the head group of phospholipids. Meanwhile, the region between 1200 and 900 $\mathrm{cm}^{-1}$ is demonstrated the symmetric stretching vibration of $\mathrm{PO}_{2}^{-}$groups in nucleic acids and C-O-C, C-O and $\mathrm{C}-\mathrm{O}-\mathrm{P}$ stretching vibrations of various oligo and polysaccharides [12-14]. The spectral analysis showed that the spectral windows from $1800-1500 \mathrm{~cm}^{-1}$ and $1500-1200 \mathrm{~cm}^{-1}$ were the regions with the greatest number of alteration effects on the different treatments and control groups of $P$. insidiosum (Fig. 2). 
Table 1 The minimal fungicidal concentrations (MFCs) of fraction No.6 from crude extract of P. stutzeri ST1302, fraction No.1 from crude extract of K. pneumoniae ST2501, and xanthyletin ( $\mathrm{mg} / \mathrm{ml}$ )

\begin{tabular}{|c|c|c|c|}
\hline Pythium insidiosum strains & $\begin{array}{l}\text { MFC of fraction No.6 } \\
\text { of crude extract from } \\
\text { P. stutzeri ST1302 (mg/ml) }\end{array}$ & $\begin{array}{l}\text { MFC of fraction No.1 } \\
\text { of crude extract from } \\
\text { K. pneumoniae ST } 2501(\mathrm{mg} / \mathrm{ml})\end{array}$ & MFC of xanthyletin $(\mathrm{mg} / \mathrm{ml})$ \\
\hline P. insidiosum SIMI-6666 & 3.125 & 1.910 & 0.003 \\
\hline P. insidiosum SIMI-2989-42 & 3.125 & 1.740 & 0.003 \\
\hline P. insidiosum SIMI-7873 & 3.125 & 1.740 & 0.003 \\
\hline P. insidiosum SIMI-7874 & 3.125 & 1.740 & 0.003 \\
\hline P. insidiosum MCC29 & 3.125 & 1.570 & 0.003 \\
\hline P. insidiosum MCC5 & 3.125 & 1.570 & 0.003 \\
\hline P. insidiosum SIMI-18093 & 3.125 & 1.570 & 0.003 \\
\hline P. insidiosum SIMI-322-37 & 3.125 & 1.570 & 0.003 \\
\hline P. insidiosum SIMI-8659 & 3.125 & 1.570 & 0.003 \\
\hline P. insidiosum SIMI-8727 & 3.125 & 1.570 & 0.003 \\
\hline P. insidiosum SIMI-9743 & 3.125 & 1.570 & 0.003 \\
\hline
\end{tabular}

Fig. 2 reveals the raw spectra (upper lines) and the spectra from the second derivative and EMSC processing (lower lines), derived from the average spectra of the whole spectral range $\left(3000-900 \mathrm{~cm}^{-1}\right)$ of the 5 groups (Negative control, Positive control, $P$. insidiosum treated by anti- $P$. insidiosum that extracted from $P$. stutzeri ST1302, $P$. insidiosum treated by anti- $P$. insidiosum that extracted from $K$. pneumoniae ST2501, and $P$. insidiosum treated by xanthyletin). The average second derivative and EMSC spectra showed an amide I peak at $1652 \mathrm{~cm}^{-1}, 1537 \mathrm{~cm}^{-1}$ of amide II and $\mathrm{P}=\mathrm{O}$ stretching vibration of phospholipids at $1243 \mathrm{~cm}^{-1}$. Moreover, the spectral windows from 1800 to $1200 \mathrm{~cm}^{-1}$ exhibited seven peaks, including at 1714, 1652, 1591, 1537, 1483, 1297 and $1243 \mathrm{~cm}^{-1}$ which are different points in the five spectra groups.

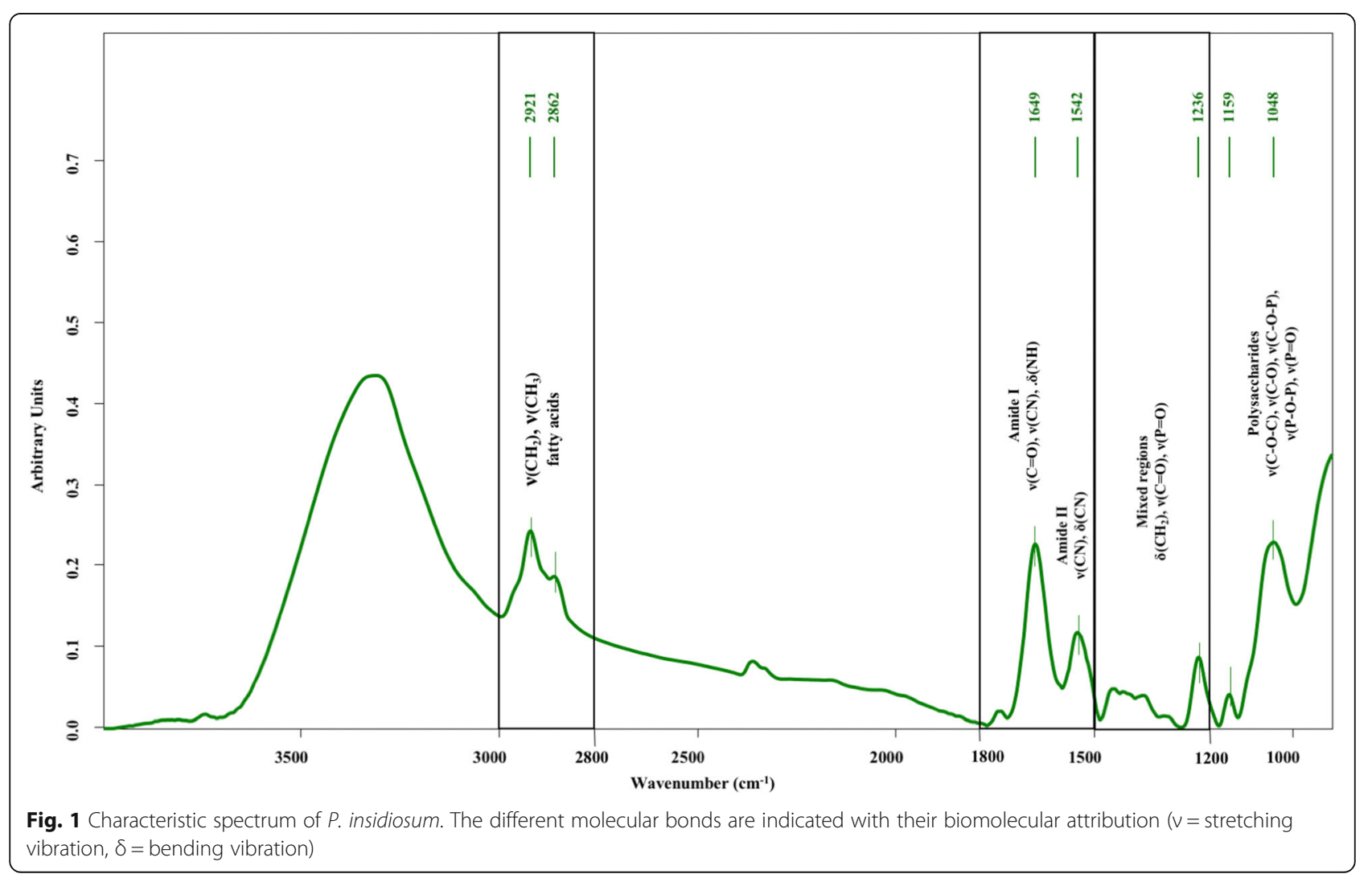




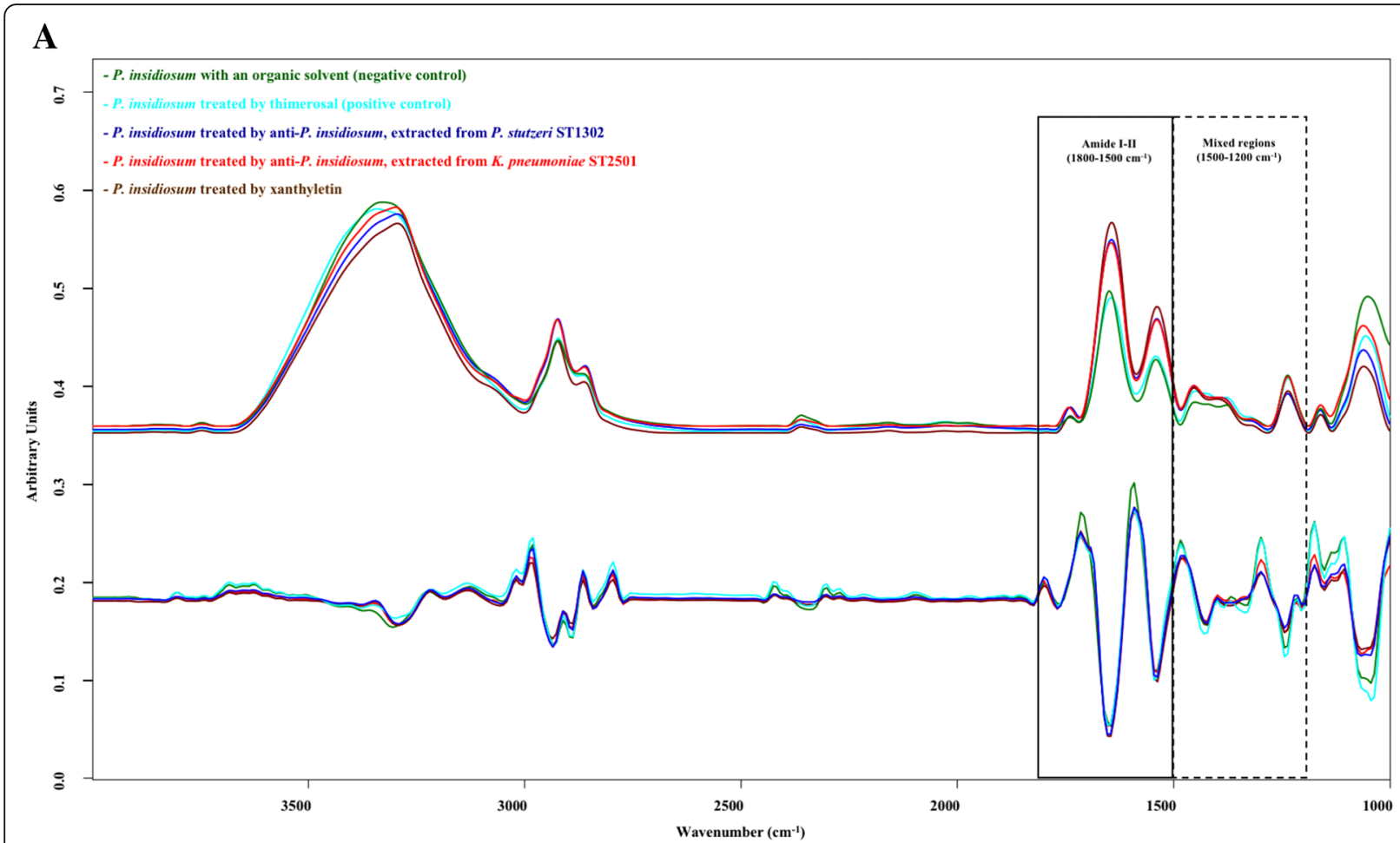

B

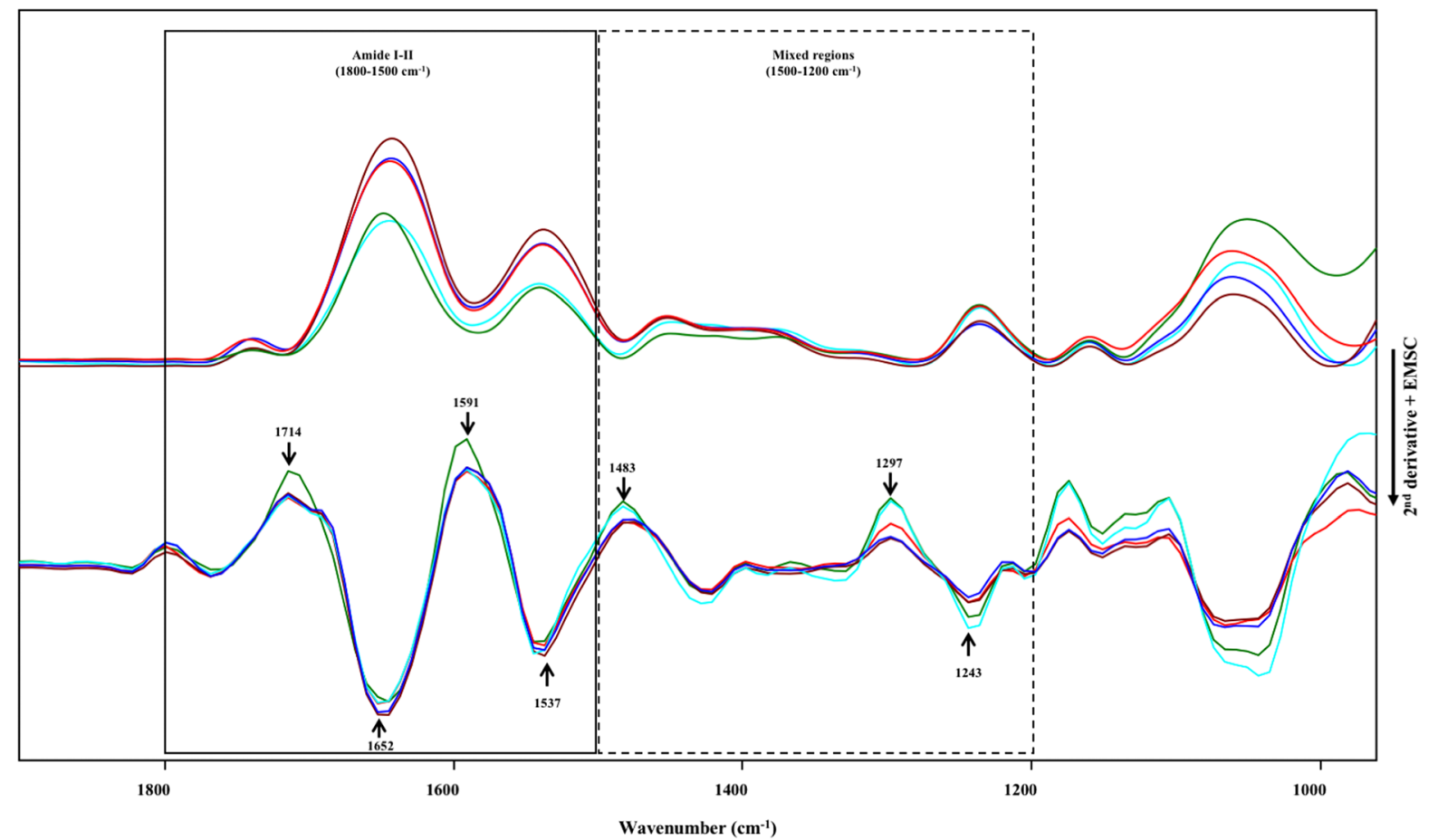

Fig. 2 The average spectra of $P$. insidiosum with treated and control groups. a The raw average spectra model (upper lines) derived from $P$. insidiosum with an organic solvent as the negative control (green), $P$. insidiosum treated by thimerosal as the positive control (sky blue) and $P$. insidiosum with the three differences treated by xanthyletin (carmine) and anti-P. insidiosum substances that extracted from P. stutzeri ST1302 (navy) and K. pneumoniae ST2501 (red) showed the pattern of the whole spectrum (4000-900 $\mathrm{cm}^{-1}$ ). All the average spectra from the second derivative and EMSC processing (lower lines) demonstrated the different regions in the spectral range of 1800-1500 $\mathrm{cm}^{-1}$ (protein region) and $1500-1200 \mathrm{~cm}^{-1}$ (mixed region). b Enlarging image at the average spectral range 1900-900 $\mathrm{cm}^{-1}$ revealed clearly differences points in proteins and mixed regions of the spectra which managed by the second derivative and EMSC, whereas the raw average spectra were not seen 


\section{Chemometric analysis}

PCA was performed in four regions; $3000-2800 \mathrm{~cm}^{-1}$ as a fatty acid region corresponding to lipid membrane, $1800-1500 \mathrm{~cm}^{-1}$ as an amide I and II region corresponding to proteins and peptides, $1500-1200 \mathrm{~cm}^{-1}$ as a mixed region containing vibrations of fatty acids, proteins, and polysaccharide, and $1200-900 \mathrm{~cm}^{-1}$ as a polysaccharide region corresponding to carbohydrates. Each sample showed absorption bands in all four areas. We found significant differences between the treated and the control groups, in both the amide I and amide II region (Fig. 3) as well as in the mixed region (Fig. 4).

Fig. 3 shows the PC scores plot and loadings plot obtained from the second derivative and EMSC spectra in the amide I and amide II region $\left(1800-1500 \mathrm{~cm}^{-1}\right)$. The two dimensional of $\mathrm{PC}$ scores plot (PC1 and $\mathrm{PC} 2$ ) showed $68 \%$ of the total variance. The PC1 (55\%) was reliable for the separation of $P$. insidiosum from the treatment groups, the positive control and the negative control. The PC2 (13\%) explains the variation within each group. The loadings plot revealed a significant peak shift at the amide I $\left(1646 \mathrm{~cm}^{-1}\right.$ shift to $\left.1621 \mathrm{~cm}^{-1}\right)$ and amide II $\left(1546 \mathrm{~cm}^{-1}\right.$ shift to $\left.1523 \mathrm{~cm}^{-1}\right)$, representing the effect of thimerosal and anti-P. insidiosum on the amide I and amide II structure of $P$. insidiosum.

Fig. 4 shows the PC scores plot and loadings plot obtained from the second derivative and EMSC spectra in the mixed region $\left(1500-1200 \mathrm{~cm}^{-1}\right)$. The two dimensional of PC scores plot (PC1 and PC2) showed $61 \%$ of the total variance. The PC1 (44\%) was responsible for the separation of $P$. insidiosum from the treatment and control groups, in which the positive and negative controls were distributed in the same area and were separated from treatment groups. The PC2 (17\%) explains the variation within each group. The loading plot revealed a significant peak shift at the $\mathrm{CH}_{2}$ bending mode of lipids and proteins $\left(1482 \mathrm{~cm}^{-1}\right.$ shift to $\left.1459 \mathrm{~cm}^{-1}\right)$ and $\mathrm{P}=\mathrm{O}$ asymmetric stretching vibrations in the head group of phospholipids $\left(1239 \mathrm{~cm}^{-1}\right.$ shift to $\left.1218 \mathrm{~cm}^{-1}\right)$.

Fig. 5 shows the PC scores plot and loadings plot obtained from the second derivative and EMSC spectra in the fatty acid region $\left(3000-2800 \mathrm{~cm}^{-1}\right)$. The two dimensional of PC scores plot (PC1 and PC3) showed $66 \%$ of the total variance. The PC3 was reliable for the separation of $P$. insidiosum from the treatment and control groups, in which the positive and negative controls were distributed in the same area and were slightly separated from the treatment groups. However, PC3 explained $10 \%$ of the separation of the sample groups, while PC1 showed $56 \%$ of the variation within each group. The PCA from the second derivative and EMSC spectra in the polysaccharides region $\left(1200-900 \mathrm{~cm}^{-1}\right)$ couldn't separate in any of the sample groups [13-15].

The PCA results of the four regions show that the protein components were changed in all the groups that were treated with anti- $P$. insidiosum substances and the positive control, whereas the mixed regions containing lipids, proteins and phospholipids were changed in the three groups which were treated with xanthyletin and secondary metabolites from bacteria. No significant differences were found in the fatty acid and polysaccharide regions in all the sample groups.

\section{Discussion}

Antagonistic microorganisms play a major role in microbial equilibrium and serve as powerful agents for biological disease control [16]. Pseudomonas stutzeri has been used to control fungal diseases in plants incited by Fusalium solani, Fusarium oxysporum, Fusarium moniliformae, Fusarium udum, Macrophomena phaseolina, Rhizoctonia solani, Colletotrichum capsicii, Aspergillus flavus, and Aspergillus niger [17]. Moreover, Klebsiella
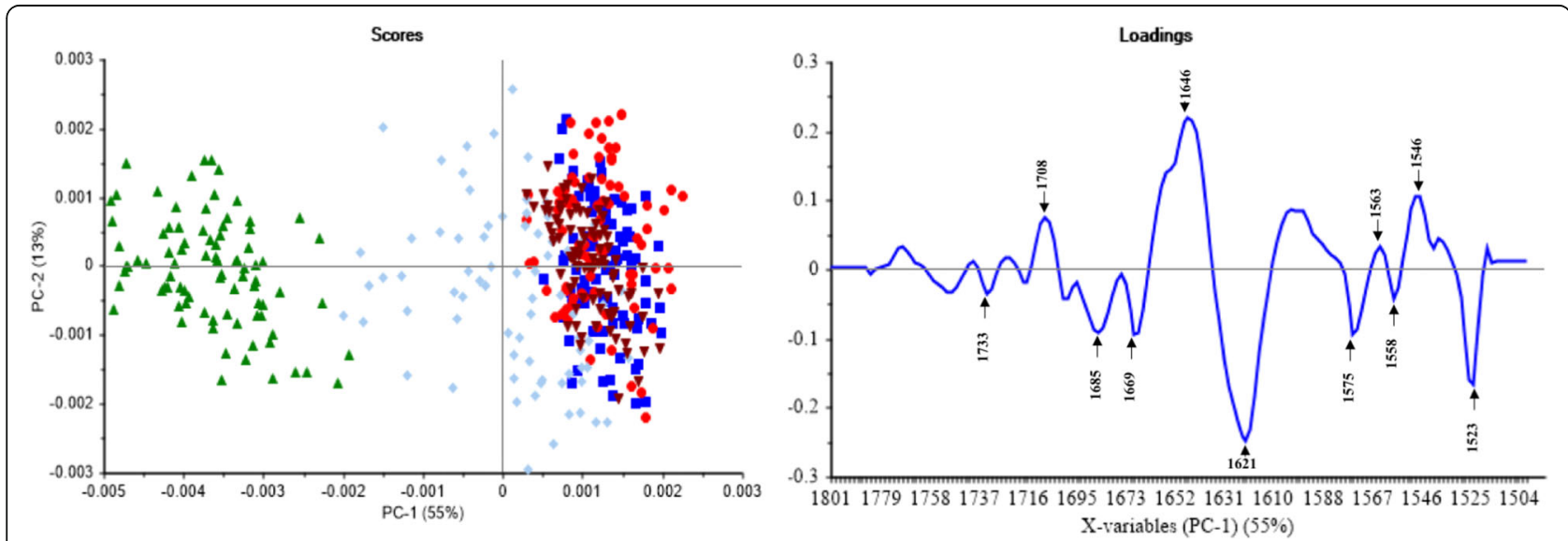

Fig. 3 The PC scores plot and loadings plot from the PCA of 1800-1500 $\mathrm{cm}^{-1}$. $\boldsymbol{\Delta}$ P. insidiosum with an organic solvent (negative control), $P$. insidiosum treated by thimerosal (positive control), $\mathbf{P}$. insidiosum treated by anti- $P$. insidiosum that extracted from $P$. stutzeri ST1302, $P$. insidiosum treated by anti-P. insidiosum that extracted from K. pneumoniae ST2501, and $\boldsymbol{\nabla} P$. insidiosum treated by xanthyletin 

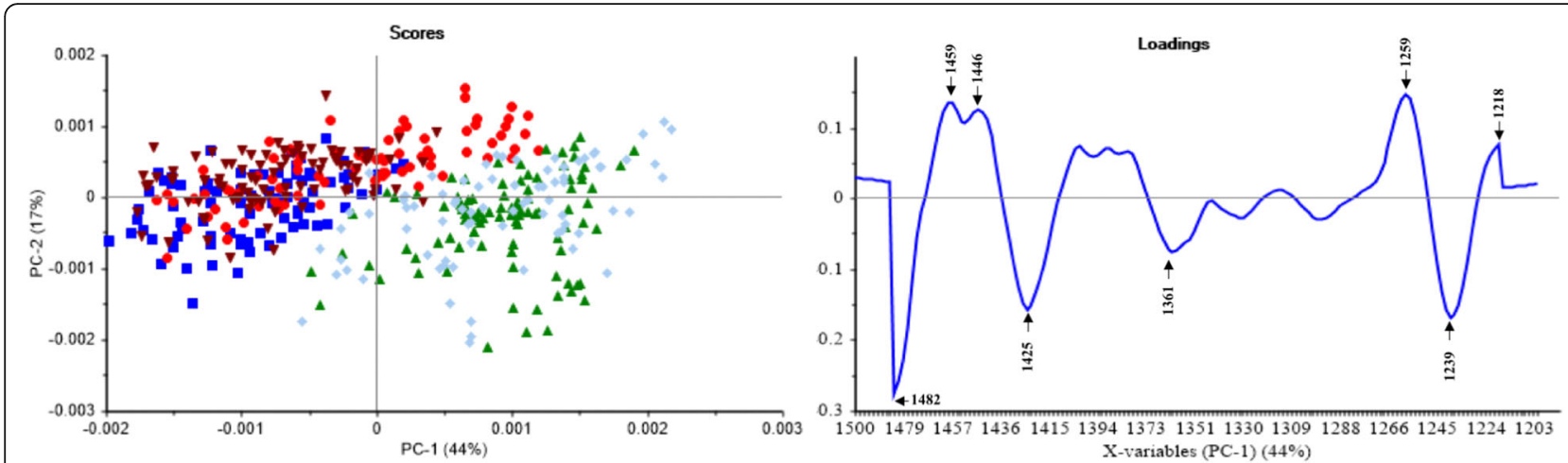

Fig. 4 The PC scores plot and loadings plot from the PCA of 1500-1200 $\mathrm{cm}^{-1}$. $\mathbf{\Delta} P$. insidiosum with an organic solvent (negative control), $c c P$. insidiosum treated by thimerosal (positive control), $\square$ P. insidiosum treated by anti-P. insidiosum that extracted from P. stutzeri ST1302, • P. insidiosum treated by anti-P. insidiosum that extracted from K. pneumoniae ST2501, and $\boldsymbol{\nabla}$ P. insidiosum treated by xanthyletin

pneumoniae exhibits anti-fungal activity through secreted bioactive compounds that suppress the growth of Aspergillus flavus, Aspergillus fumigatus, Candida albicans, Penicillium expansum, Aspergillus niger and Aspergillus terreus. Abeer et al. reported that $100 \mathrm{mg} / \mathrm{mL}$ of crude extract from $K$. pneumoniae gave higher diameter zones of inhibition than $30 \mu \mathrm{g} / \mathrm{mL}$ of amphotericin B, fluconazol and miconazole nitrate when used against $A s$ pergillus flavus [18]. In the present study, crude extracts and fractions from $K$. pneumoniae ST2501 gave stronger anti- $P$. insidiosum activity and stability than the crude extracts and fractions from $P$. stutzeri ST1302. This was due to $K$. pneumoniae ST2501 producing many more important secondary metabolites with high biological activities when compared to P. stutzeri ST1302. Abeer Fauzi Al-Rubaye et al. [18], reported that K. pneumoniae produces many important secondary metabolites with high biological activities as anti-fungal activity.

Coumarins are members of a class of compounds called benzopyrones, which consist of fused benzene and $\alpha$-pyrone rings. Most coumarins are secondary metabolites of green plants, but some coumarins are produced by fungi and bacteria. Xanthyletin is a member of pyranocoumarins (coumarin derivatives) and has been shown to have anti-fungal activity against Candida albicans and filamentous fungi [19]. Of the tested compounds in the present study, xanthyletin had the strongest anti- $P$. insidiosum activity. The observed MFC of $0.003 \mathrm{mg} / \mathrm{ml}$ correlated well with compound 5 from the fruits of Scaevola taccada that showed anti-P. insidiosum activity with the MIC of $0.005 \mathrm{mg} / \mathrm{ml}$ [7]. A higher potential for xanthyletin activity against $P$. insidiosum hyphae is promising for the development of antimicrobial drugs against pythiosis.

Synchrotron radiation-based FTIR microspectroscopy was used to for the identification of filamentous fungi along with analyzed spectra data and statistical analysis of biomolecular discrimination $[9,10]$. This is the first study of $P$. insidiosum hyphae by synchrotron radiation-based FTIR microspectroscopy that shows the spectral data specific to functional groups of biological molecules such as proteins, lipids, and carbohydrates.
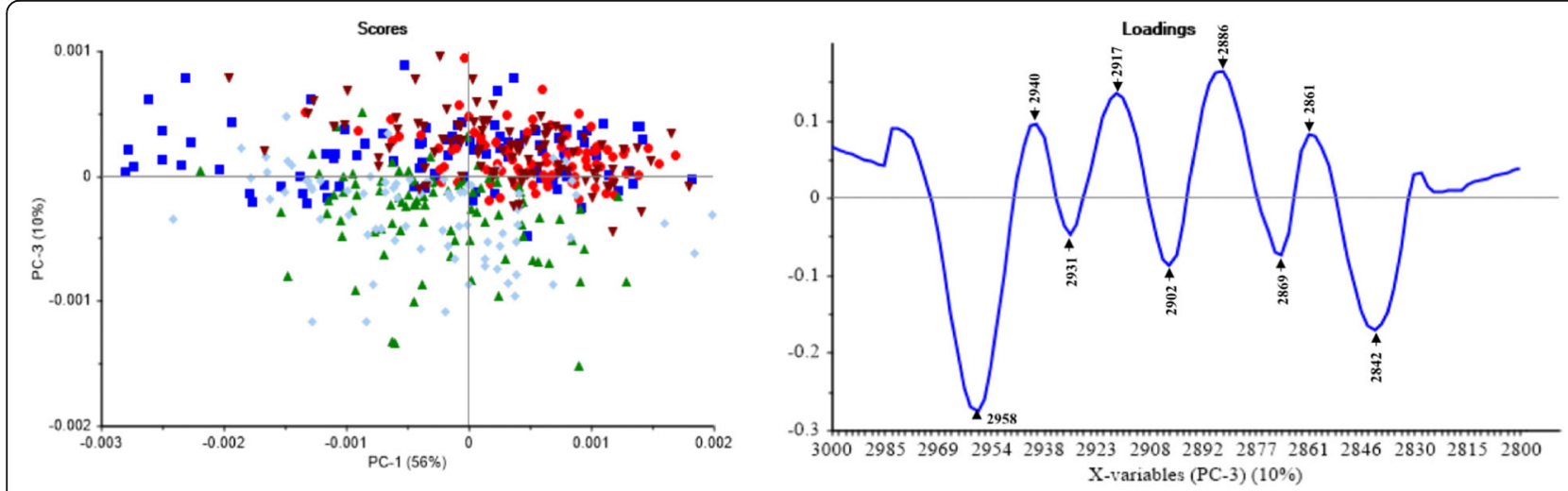

Fig. 5 The PC scores plot and loadings plot from the PCA of $3000-2800 \mathrm{~cm}^{-1}$. $\boldsymbol{\Delta} P$. insidiosum with an organic solvent (negative control), $\boldsymbol{\Delta} P$. insidiosum treated by thimerosal (positive control), $\mathbf{P}$. insidiosum treated by anti- $P$. insidiosum that extracted from $P$. stutzeri ST1302, $\bullet$. insidiosum treated by anti-P. insidiosum that extracted from K. pneumoniae ST2501, and $\boldsymbol{\nabla} P$. insidiosum treated by xanthyletin 
Statistical analysis of the FTIR spectra found protein changes in P. insidiosum when treated using thimerosal (positive control), the three sample groups treated with xanthyletin, and two anti-P. insidiosum substances from P. stutzeri ST1302 and K. pneumoniae ST2501. However, the pattern of the proteins changes in the positive control and the three treated sample groups were different. Thimerosal's anti-microbial action is dependent on it breaking down and releasing ethyl-mercury to penetrate the cell membranes and binds to intracellular enzymes, which then inhibits them and causes cell death [20]. Interestingly, previous studies have shown that some anti-bacterial drugs, such as aminoglycosides, tetracyclines and macrolides, exhibit inhibitory activity against $P$. insidiosum, but the MICs are incompatible with safe plasma levels $[21,22]$. While the mechanism of action of these anti-bacterial drugs against eukaryotic organisms is not entirely understood, their mechanisms are similar to be similar to that described for P. ultimum: reduced incorporation of amino acids into proteins, inhibition of protein synthesis, and inhibition of amino acid transport [23]. Therefore, we propose that the target molecule of the xanthyletin and the secondary metabolites from $P$. stutzeri ST1302 and K. pneumoniae ST2501 might be protein components of this organism.

\section{Conclusion}

In vitro studies of xanthyletin and the secondary metabolites from $P$. stutzeri ST1302 and K. pneumoniae ST2501 showed anti- $P$. insidiosum activity, characterized by clearly changed proteins in $P$. insidiosum. Future study should seek to include proteomics analysis to improve understanding about the mechanism of anti- $P$. insidiosum activity and an in vivo study of these anti- $P$. insidiosum extracts.

\section{Methods}

\section{Microorganisms preparation}

Pythium insidiosum preparation: Eleven clinical strains of $P$. insidiosum, isolated from the ocular, vascular, and disseminated forms of human pythiosis were identified by Assoc. Prof. Dr. Angkana Chaiprasert, Department of Microbiology, Mahidol University. These organisms were rechecked by culture on Sabouraud Dextrose Agar at $25^{\circ} \mathrm{C}$, detect perpendicular sparsely septate hyphae under the light microscope, induced zoospore formation and PCR identification [8]. The cultures were maintained on Sabouraud Dextrose Agar at room temperature and sub-cultured once a month. This study was approved by the Center for Ethics in Human Research, Khon Kaen University (number HE592105).

Pseudomonas stutzeri ST1302 and Klebsiella pneumoniae ST2501 preparation. P. stutzeri ST1302 and K. pneumoniae ST2501 that produced anti-P. insidiosum substances were isolated from water sampling area around Khon Kaen University and identified by Dr. Yordhathai Thongsri [8]. The microorganisms were rechecked by the automated Vitex2 system and preserved in skimmed milk with $15 \%$ glycerol and then frozen at $-20^{\circ} \mathrm{C}$.

Xanthyletin: Commercially xanthyletin $\left(\mathrm{C}_{14} \mathrm{H}_{12} \mathrm{O}_{3}\right)$ powder as a coumarin compound was obtained from ChemFaces (Wuhan, China). It showed $98 \%$ of purity tested and 228.24 of molecular weight.

\section{Crude extraction from $P$. stutzeri ST1302 and $K$. pneumoniae ST2501}

The P. stutzeri ST1302 and K. pneumoniae ST2501 inoculants were prepared to McFarland Standard No.1 $(3 \times$ $\left.10^{8} \mathrm{CFU} / \mathrm{ml}\right), 700 \mu \mathrm{l}$ of this concentration was inoculated by aseptic technique into six $1000 \mathrm{ml}$ bottles, each of which contained $700 \mathrm{ml}$ of brain heart infusion (BHI) broth. Each bottle was then incubated on a rotary shaker at $200 \mathrm{rpm}$ at $37^{\circ} \mathrm{C}$ for 3 days. Then, 4.21 of culture broth was centrifuged at $7500 \mathrm{rpm}$ for $20 \mathrm{~min}$ at $4{ }^{\circ} \mathrm{C}$ and sterilized by filtration through a $0.45 \mu \mathrm{m}$ pore size membrane filter (Millipore). Cell free filtrate was concentrated ten-fold in a rotary evaporator (Rotavapor R-210, Buchi). Four hundred and twenty milliliter of the cultured broth was then mixed three times with a two-fold volume of dichloromethane (Fisher) for P. stutzeri ST1302, and ethyl acetate (Fisher) for K. pneumoniae ST2501. Each dichloromethane and ethyl acetate layer was then dried with anhydrous $\mathrm{Na}_{2} \mathrm{SO}_{4}$ (Merck) and concentrated in a rotary evaporator (Rotavapor R-210, Buchi).

\section{Separation of the crude extracts from P. stutzeri ST1302 and $K$. pneumoniae ST2501}

The crude extracts from P. stutzeri ST1302 and K. pneumoniae ST2501 were fractionated by activity-guided separation liquid column chromatography (LCC). The extracts were applied to a glass column filled with a slurry of silica gel $60(0.015-0.040 \mathrm{~mm}$; Merck), which had been preconditioned with dichloromethane for the crude extract from P. stutzeri ST1302, and with ethyl acetate for the crude extract from $K$. pneumoniae ST2501. Gradient mixtures of dichloromethane and methanol were used as mobile phases. The eluent was collected and fractions defined according to their thin layer chromatography (TLC) characteristics. TLC was using silica gel GF254 pre-coated aluminum sheets. The fractions containing the same major compounds were combined and tested for anti-P. insidiosum activity using the disc diffusion method described in the following section. The fraction with inhibitory activity from $P$. stutzeri ST1302 was separated again using LCC with gradient mixtures of dichloromethane and hexane (Merck) as 
mobile phases. TLC was then used for the differentiation of single fractions according to retention factors $\left(\mathrm{R}_{\mathrm{f}}\right)$ and to check purity. Detection was under exposure to UV light at 256 and $364 \mathrm{~nm}$.

\section{Anti-P. insidiosum activity by disc diffusion method}

Testing solutions, including the whole crude extract, fractions of the crude extract and xanthyletin, were tested for anti- $P$. insidiosum activity. The testing solutions were prepared as $500 \mathrm{mg} / \mathrm{ml}$ stock solutions. Paper discs (6 mm in diameter; Gibthai, Thailand) were placed onto SDA plates with $P$. insidiosum and grown for 2 days, and $20 \mu$ of each testing solution was added to the discs (dichloromethane and ethyl acetate were used as a negative controls). The testing plates were stored at room temperature for $2 \mathrm{~h}$ in a laminar flow biosafety cabinet to testing the solution diffusion and they were then incubated at $37^{\circ} \mathrm{C}$ for 3,6 and 9 days. Inhibition zones were measured when the growth of $P$. insidiosum reached the negative control discs.

\section{Broth dilution susceptibility testing}

To investigate the in vitro anti- $P$. insidiosum effect of the crude extract from the bacteria and xanthyletin, we used the method of Rodrigo Trolezi et al. with some modifications [24]. Briefly, fragments of P. insidiosum mycelia ( $5 \mathrm{~mm}$ in diameter) from the SDA plates were inoculated by aseptic technique into $1.95 \mathrm{ml}$ of Sabouraud Dextrose Broth (SDB) and incubated at $37^{\circ} \mathrm{C}$ for 3 days. Fifty microliters of varying concentrations of the testing solutions that had anti- $P$. insidiosum activity were added to the cultures and incubated at $37^{\circ} \mathrm{C}$ for $24 \mathrm{~h}$. Fifty microliters of organic solvent, which dissolved the anti- $P$. insidiosum substances, was added and incubated at $37^{\circ} \mathrm{C}$ for $24 \mathrm{~h}$ as the negative control. The $P$. insidiosum fragments were then placed on SDA plates and incubated at $37^{\circ} \mathrm{C}$ for 3,6 and 9 days to follow the hyphal growth and determine the minimal fungicidal concentration (MFC). All tests were performed in triplicate.

\section{Sample preparation for FTIR microspectroscopy}

According to the broth dilution susceptibility testing, the MFC of each testing solution was selected for FTIR microspectroscopy analysis. $P$. insidiosum treated by $0.02 \%(w / v)$ thimerosal was selected as the positive control, while $P$. insidiosum mycelia fragments in SDB plus organic solvent was selected as the negative control. After incubation, $1 \mathrm{ml}$ of individual mycelia were collected and transferred to an Eppendorf tube and centrifuged $(430 \mathrm{x} \mathrm{g}$ for $30 \mathrm{~s})$ to remove the culture supernatant. The mycelia were then washed 3 times by $1 \mathrm{ml}$ of $0.9 \% \mathrm{NaCl}$ by centrifugation ( $430 \mathrm{x} \mathrm{g}$ for $30 \mathrm{~s}$ ) and the supernatant was discarded. Mycelial pellets were resuspended in $300 \mathrm{ml}$ of $0.9 \% \mathrm{NaCl}$ before FTIR microspectroscopy analysis.

\section{FTIR-spectral acquisition and pre-processing}

Five microliters of mycelia suspension were placed on a calcium fluoride $\left(\mathrm{CaF}_{2}\right)$ window for synchrotron radiation-based Fourier transform infrared (FTIR) microspectroscopy investigation. The $\mathrm{CaF}_{2}$ windows were dried in a class II biological safety cabinet (BSC) for $30 \mathrm{~min}$ and kept in the desiccator until FTIR investigations to avoid the influence of water absorption on the infrared spectra. FTIR spectra were acquired using a Hyperion 2000 IR microscope coupling with a Vertex 70 spectrometer (BRUKER Optics GmbH, Ettlingen, Germany). The internal light source was replaced by synchrotron light delivered from the front-end of Beamline 4.1: IR at Synchrotron Light Research Institute (Thailand). The spectra were recorded in transmission mode using a $15 \mathrm{x}$ objective, 64 accumulations per sample, a spectral resolution of $4 \mathrm{~cm}^{-1}$, and a spectral range of $4000-900 \mathrm{~cm}^{-1}$. Before the samples were measured, the background spectrum of the $\mathrm{CaF}_{2}$ window was recorded and then subtracted from the sample signal. Pre-processing of infrared spectra included the region $4000-900 \mathrm{~cm}^{-1}$, all spectral data were extracted by OPUS software (version 7.2, Bruker Optics GmbH, Ettlingen, Germany).

\section{Chemometric analysis}

Principal Component Analysis (PCA) was performed using Unscrambler software (version 10.5, CAMO software AS, Norway) to classify the samples using their explained variables in the following spectral ranges; 3000$2800 \mathrm{~cm}^{-1}$ as the fatty acid region (corresponding to lipid membrane), $1800-1500 \mathrm{~cm}^{-1}$ as the amide I and II region (corresponding to proteins and peptides), 1500$1200 \mathrm{~cm}^{-1}$ as the mixed region containing vibrations of free fatty acids, proteins, and phospholipids, and 1200$900 \mathrm{~cm}^{-1}$ as the polysaccharide region (corresponding to carbohydrates). The second derivative was performed with Savitzky Golay 19-point smoothing which removed the broad baseline offset. In addition, the final spectra were taken as an extended multiplicative scatter correction (EMSC), which eliminated the physical information collected from the light scattering and removed artefacts that were introduced from normalizing the path length differences. This ensured that the spectra obtained would only be from the functional groups of the biomolecules. The EMSC corrected data is a robust representation of the biomolecules present. After the EMSC processing, the samples were classified using principal component analysis (PCA). 


\section{Abbreviations}

FTIR: Fourier transform infrared; MFC: Minimal fungicidal concentration; PC: Principal component; PCA: Principal component analysis; SDA: Sabouraud dextrose agar; SDB: Sabouraud dextrose broth

\section{Acknowledgements}

The authors are grateful to the Centre for Research and Development of the Medical Diagnostic Laboratories, Faculty of Associated Medical Sciences, Graduate School, Khon Kaen University, Khon Kaen and Synchrotron Light Research Institute (Public Organization), Nakhon Ratchasima, Thailand for using its laboratory facility. The authors thank Dr. Glenn N. Borlace, Faculty of Pharmaceutical Sciences, Khon Kaen University, Khon Kaen, Thailand for English language assistance.

\section{Funding}

This research was supported by the Thailand Research Fund (TRF) through the Royal Golden Jubilee Ph.D. Program (Grant no. PHD/0174/2556) and Research and Technology Transfer Affairs (KKUSyn60_007), Khon Kaen University, Khon Kaen, Thailand.

\section{Availability of data and materials}

Data will be shared upon request to the corresponding author chupra@kku. ac.th

\section{Authors' contributions}

KW carried out all experiments, data analysis, and manuscript writing. MP, RT and CP participated in the design of the study and in the manuscript writing. SL, CY and SCS collaborated in separation of crude extract, in vitro studies and FTIR microspectroscopy analysis, manuscript writing. All authors have read and approved the final manuscript.

\section{Ethics approval and consent to participate}

This studies were approved by the Center for Ethics in Human Research, Khon Kaen University (number HE592105).

\section{Competing interests}

The authors declare that they have no competing interests.

\section{Publisher's Note}

Springer Nature remains neutral with regard to jurisdictional claims in published maps and institutional affiliations.

\section{Author details}

'Department of Clinical Microbiology, Faculty of Associated Medical Sciences, Centre for Research and Development of Medical Diagnosis Laboratories, Khon Kaen University, Khon Kaen 40002, Thailand. 'Department of Chemistry, Faculty of Science, Khon Kaen University, Khon Kaen 40002, Thailand. ${ }^{3}$ Synchrotron Light Research Institute (Public Organization), Nakhon Ratchasima 30000, Thailand.

Received: 30 November 2018 Accepted: 2 April 2019

Published online: 16 April 2019

\section{References}

1. De Cock AW, Mendoza L, Padhye AA, Ajello L, Kaufman L. Pythium insidiosum sp. nov., the etiologic agent of pythiosis. J Clin Microbiol. 1987; 25(2):344-9.

2. Mendoza L, Hernandez F, Ajello L. Life cycle of the human and animal oomycete pathogen Pythium insidiosum. J Clin Microbiol. 1993;31(11):2967-73.

3. Mendoza $L$, Prendas J. A method to obtain rapid zoosporogenesis of Pythium insidiosum. Mycopathologia. 1988;104(1):59-62.

4. Chaiprasert A, Samerpitak K, Wanachiwanawin W, Thasnakorn P. Induction of zoospore formation in Thai isolates of Pythium insidiosum. Mycoses. 1990:33(6):317-23.

5. Thianprasit M, Chaiprasert A, Imwidthaya P. Human pythiosis. Curr Top Med Mycol. 1996;7(1):43-54

6. Triscott JA, Weedon D, Cabana E. Human subcutaneous pythiosis. J Cutan Pathol. 1993;20(3):267-71.

7. Suthiwong J, Thongsri Y, Yenjai C. A new furanocoumarin from the fruits of Scaevola taccada and antifungal activity against Pythium insidiosum. Nat Prod Res. 2017;31(4):453-9.
8. Thongsri Y, Aromdee C, Yenjai C, Kanokmedhakul S, Chaiprasert A, Hamal P, et al. Detection of diketopiperazine and pyrrolnitrin, compounds with antiPythium insidiosum activity, in a pseudomonas stutzeri environmental strain. Biomed Pap Med Fac Univ Palacky Olomouc Czech Repub. 2014; 158(3):378-83.

9. Lecellier A, Gaydou V, Mounier J, Hermet A, Castrec L, Barbier G, et al. Implementation of an FTIR spectral library of 486 filamentous fungi strains for rapid identification of molds. Food Microbiol. 2015;45(Pt A:126-34.

10. Lecellier A, Mounier J, Gaydou V, Castrec L, Barbier G, Ablain W, et al. Differentiation and identification of filamentous fungi by high-throughput FTIR spectroscopic analysis of mycelia. Int J Food Microbiol. 2014;168(169):32-41.

11. Holman HYN, Bechtel HA, Hao Z, Martin MC. Synchrotron IR Spectromicroscopy: chemistry of living cells. Anal Chem. 2010;82(21):8757-65.

12. Mularczyk-Oliwa M, Bombalska A, Kaliszewski M, Włodarski M, Kwaśny M, Kopczyński K, Szpakowska M, Trafny EA. Rapid discrimination of several fungus species with FTIR spectroscopy and statistical analysis. Bull Military Univ Technol. 2013;LXII:10.

13. Mla K, Muromtsev SN. Application of infrared spectroscopy in microbiology: review of literature. Vestn Akad Med Nauk SSSR. 1960;15(6):59-71.

14. Corte L, Tiecco M, Roscini L, De Vincenzi S, Colabella C, Germani R, et al. FTIR metabolomic fingerprint reveals different modes of action exerted by structural variants of $\mathrm{N}$-alkyltropinium bromide surfactants on Escherichia coli and Listeria innocua cells. PLoS One. 2015;10(1):e0115275

15. Mester $\mathrm{P}, \mathrm{AKJ} \mathrm{CL}$, Kalb R, Grunert T, Rossmanith P. FTIR metabolomic fingerprint reveals different modes of action exerted by active pharmaceutical ingredient based ionic liquids (API-ILS) on Salmonella typhimurium. RSC Adv. 2016;6(38):7.

16. Lim HS, Kim YS, Kim SD. Pseudomonas stutzeri YPL-1 genetic transformation and antifungal mechanism against Fusarium solani, an agent of plant root rot. Appl Environ Microbiol. 1991;57(2):510-6.

17. Prasanna ND, Vijayalakshmi K, Seshagirirao K, Shaheen SK. Characterization of antifungal compounds produced by Pseudomonas stutzeri (EGB3) isolated from gut of earthworm (Eisenia foetida). J Microbiol Antimicrobials. 2014:6(3):9.

18. Al-Rubaye AF, Kadhim MJ, Hameed $\mathrm{IH}$. Characterization of antifungal secondary metabolites produced by Klebsiella pneumoniae and screening of its chemical compounds using GC-MS. Int J Curr Pharmaceutical Rev Res. 2017:8(2):8.

19. Montagner C, de Souza SM, Groposoa C, Delle Monache F, Smania EF, Smania A Jr. Antifungal activity of coumarins. Z Naturforsch C. 2008;63(1-2):21-8.

20. Jin BS, Han SG, Lee WK, Ryoo SW, Lee SJ, Suh SW, et al. Inhibitory mechanism of novel inhibitors of UDP-N-acetylglucosamine enolpyruvyl transferase from Haemophilus influenzae. J Microbiol Biotechnol. 2009; 19(12):1582-9.

21. Jesus FP, Ferreiro $L$, Loreto ES, Pilotto MB, Ludwig A, Bizzi $K$, et al. In vitro synergism observed with azithromycin, clarithromycin, minocycline, or tigecycline in association with antifungal agents against Pythium insidiosum. Antimicrob Agents Chemother. 2014;58(9):5621-5.

22. Jesus FP, Loreto ES, Ferreiro L, Alves SH, Driemeier D, Souza SO, et al. In vitro and in vivo antimicrobial activities of minocycline in combination with azithromycin, clarithromycin, or Tigecycline against Pythium insidiosum. Antimicrob Agents Chemother. 2016;60(1):87-91.

23. Loreto ES, Mario DA, Denardi LB, Alves SH, Santurio JM. In vitro susceptibility of Pythium insidiosum to macrolides and tetracycline antibiotics. Antimicrob Agents Chemother. 2011;55(7):3588-90.

24. Trolezi R, Azanha JM, Paschoal NR, Chechi JL, Dias Silva MJ, Fabris VE, et al. Stryphnodendron adstringens and purified tannin on Pythium insidiosum: in vitro and in vivo studies. Ann Clin Microbiol Antimicrob. 2017:16(1):7.

Ready to submit your research? Choose BMC and benefit from:

- fast, convenient online submission

- thorough peer review by experienced researchers in your field

- rapid publication on acceptance

- support for research data, including large and complex data types

- gold Open Access which fosters wider collaboration and increased citations

- maximum visibility for your research: over $100 \mathrm{M}$ website views per year

At BMC, research is always in progress.

Learn more biomedcentral.com/submissions 